\title{
Electrical Conduction and Dielectric Breakdown in Aluminum Oxide Insulators on Silicon
}

\author{
James Kolodzey, Senior Member, IEEE, Enam Ahmed Chowdhury, Thomas N. Adam, Guohua Qui, I. Rau, \\ Johnson Olufemi Olowolafe, John S. Suehle, Senior Member, IEEE, and Yuan Chen
}

\begin{abstract}
Leakage currents and dielectric breakdown were studied in MIS capacitors of metal-aluminum oxide-silicon. The aluminum oxide was produced by thermally oxidizing AIN at $800-1100{ }^{\circ} \mathrm{C}$ under dry $\mathrm{O}_{2}$ conditions. The AIN films were deposited by RF magnetron sputtering on p-type $\mathrm{Si}(100)$ substrates. Thermal oxidation produced $\mathrm{Al}_{2} \mathrm{O}_{3}$ with a thickness and structure that depended on the process time and temperature. The MIS capacitors exhibited the charge regimes of accumulation, depletion, and inversion on the $\mathrm{Si}$ semiconductor surface. The best electrical properties were obtained when all of the AIN was fully oxidized to $\mathrm{Al}_{2} \mathrm{O}_{3}$ with no residual $\mathrm{AIN}$. The MIS flatband voltage was near $0 \mathrm{~V}$, the net oxide trapped charge density, $Q_{\mathrm{ox}}$, was less than $10^{11} \mathrm{~cm}^{-2}$, and the interface trap density, $D_{i t}$, was less than $10^{11} \mathrm{~cm}^{-2} \mathrm{eV}^{-1}$. At an oxide electric field of 0.3 $\mathrm{MV} / \mathrm{cm}$, the leakage current density was less than $10^{-7} \mathrm{~A} \mathrm{~cm}^{-2}$, with a resistivity greater than $10^{12} \Omega$-cm. The critical field for dielectric breakdown ranged from 4 to $5 \mathrm{MV} / \mathrm{cm}$. The temperature dependence of the current versus electric field indicated that the conduction mechanism was Frenkel-Poole emission, which has the interesting property that higher temperatures reduce the current. This may be important for the reliability of circuits operating under extreme conditions. The dielectric constant ranged from 3 to 9. The excellent electronic quality of aluminum oxide may be attractive for field effect transistor applications.
\end{abstract}

Index Terms-Dielectric breakdown, MIS capacitors, MOS capacitors, semiconductor-insulator interfaces.

\section{INTRODUCTION}

$\mathbf{O}$ VER the past decade, the gate oxides of field effect transistors in commercial integrated circuits have been scaled to below $4 \mathrm{~nm}$ thick to increase the gate capacitance and the transistor gain. In thin layers, the problems associated with gate electrode breakdown and leakage currents are crucial because of quantum mechanical tunneling. Under high electric field stressing, silicon dioxide degrades by the formation of traps, leading to lower breakdown fields [1]-[4]. After prolonged periods at relatively lower fields, $\mathrm{SiO}_{2}$ may fail catastrophically by the mechanism of time dependent dielectric breakdown (TDDB), which is still not well understood [4]-[6]. Evidence indicates that the breakdown mechanism changes with the

Manuscript received July 20, 1998; revised May 12, 1999. This work was supported by the ARO under Grants DAAH04-95-1-0625 and AASERT DAAG55-97-1-0249, by DARPA under Contract F49620-96-C-0006, and by the NSF under Grant ECS-9872692. The review of this paper was arranged by Editor D. P. Verret.

J. Kolodzey, E. A. Chowdhury, T. Adam, G. Qui, I. Rau, and J. O. Olowolafe are with the Department of Electrical and Computer Engineering, University of Delaware, Newark, DE 19716 USA (e-mail: kolodzey@ee.udel.edu).

J. S. Suehle and Y. Chen are with the National Institute of Standards and Technology, Gaithersburg, MD 20899 USA.

Publisher Item Identifier S 0018-9383(00)00157-X. strength of the applied electric field, casting doubt on the suitability of high field stressing alone to predict the long-term reliability of circuits normally operating at lower fields [7]. High tunneling currents cause heating and waste power [8], and $\mathrm{SiO}_{2}$ may have difficulty sustaining further scaling reductions in thickness. Oxide scaling to zero thickness produces essentially a metal-semiconductor transistor (MESFET) [9] that may not be desirable because of the well-known limitations in drive currents and transconductance compared to MOSFET's [10]. A larger dielectric constant increases the transistor gate capacitance with higher transconductance for the same dielectric thickness, or it can be thicker for the same capacitance with less tunneling leakage current, which decreases exponentially with thickness.

For device applications, various dielectrics have been investigated as alternatives to $\mathrm{SiO}_{2}$. Oxidized AlAs is interesting for optical and electrical devices, but may contain residual arsenic [11], [12]. Tantalum pentoxide $\left(\mathrm{Ta}_{2} \mathrm{O}_{5}\right)$ can be deposited at low process temperatures and has a dielectric constant above 25 depending on its structure, but may lack long-term stability against reactions with $\mathrm{Si}$ [13], [14]. $\mathrm{Al}_{2} \mathrm{O}_{3}$ deposited by sputtering is thermally stable and mechanically hard [15][16]. Simulations indicate that sputtered $\mathrm{Al}_{2} \mathrm{O}_{3}$ may be useful in the gates of flash memory circuits because its higher dielectric constant increases the capacitive coupling and increases circuit speed by three orders of magnitude, compared to using $\mathrm{SiO}_{2}$ [17]. Unoxidized AlN has been used as a transistor gate dielectric on Si [18]. Previous studies of micron thick AlN films deposited by plasma enhanced chemical vapor deposition indicated resistance to oxidation up to $900{ }^{\circ} \mathrm{C}$, with $\mathrm{Al}_{2} \mathrm{O}_{3}$ forming above $1100{ }^{\circ} \mathrm{C}$ [19]. In general, the defect density of deposited insulators is higher than that of thermally grown insulators.

This paper describes measurements of dielectric breakdown, leakage, and tunneling in $\mathrm{Al}_{2} \mathrm{O}_{3}$ produced by thermally oxidizing thin films of AlN on p-type Si substrates, as described previously [20]-[22]. We report on the defect density, dielectric constant, resistivity, and breakdown strength. In principle, aluminum oxide could be produced by other techniques including the reactive sputtering of $\mathrm{Al}$ metal in an oxygen atmosphere [23], and spray pyrolysis [24]. The optimum oxide process for applications is not clear, so it is valuable to compare methods. The best quality $\mathrm{SiO}_{2}$ films are produced by thermal oxidation, which is the method explored here.

\section{EXPERIMENTAL PREPARATION}

The metal-insulator-silicon (MIS) capacitors were fabricated using the following procedure. First, p-type Si (100) 
TABLE I

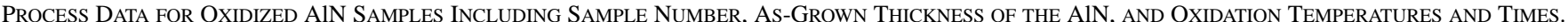
THE SUblayer THICKNESS $(d)$ was DETERMINED FROM ElLIPSOMETRY, STYLUS PROFILOMETRY, AND RBS DATA SIMULATED WITH RUMP SOFTWARE, ASSUMING a Structure Having Three Stoichiometric Layers with the Compositions Shown Here. The Substrates were Si (100) with $1 \Omega$-cm Resistivity

\begin{tabular}{|c|c|c|c|c|c|}
\hline \multicolumn{2}{|c|}{ as-deposited } & \multicolumn{4}{|c|}{ after oxidation } \\
\hline Sample & $\begin{array}{c}\text { AIN thickness } \\
(\mathbf{n m})\end{array}$ & $\begin{array}{l}\text { temp. / time } \\
\left({ }^{0} \mathrm{C}\right) /(\mathrm{hr})\end{array}$ & $\begin{array}{c}\mathrm{d}_{\mathrm{Al} 2 \mathrm{O3}} \\
(\mathrm{nm})\end{array}$ & $\begin{array}{l}\mathbf{d}_{\text {AIN }} \\
(\mathbf{n m}) \\
\end{array}$ & $\begin{array}{c}\mathrm{dSiO2} \\
(\mathrm{nm}) \\
\end{array}$ \\
\hline $100601 \mathrm{a}$ & 250 & $1100 / 2$ & 435 & 0 & 144 \\
\hline $100601 \mathrm{~b}$ & 250 & $1100 / 1$ & 452 & 0 & 76 \\
\hline $100601 \mathrm{c}$ & 250 & $1000 / 1$ & 378 & 6 & 42 \\
\hline $100601 d$ & 250 & $900 / 1$ & 90 & 203 & 0 \\
\hline $100601 \mathrm{e}$ & 250 & $800 / 1$ & 25 & 236 & 0 \\
\hline $012301 \mathrm{a}$ & 55 & $900 / 1$ & 101 & 0 & 0 \\
\hline $012301 \mathrm{~b}$ & 55 & $900 / 2$ & 101 & 0 & 0 \\
\hline $012301 \mathrm{c}$ & 55 & $900 / 3$ & 101 & 0 & 0 \\
\hline SO-9001 & - & $900 / 1$ & - & - & 27 \\
\hline SO-9002 & - & $900 / 2$ & - & - & 43 \\
\hline SO-9003 & - & $900 / 3$ & - & - & 56 \\
\hline & & & & & \\
\hline
\end{tabular}

substrates having a resistivity of $1 \Omega$-cm were degreased and acid cleaned using an RCA etch and an HF dip. The substrates were Si pieces roughly $1 \mathrm{~cm}$ wide. Layers of AlN were deposited by RF magnetron reactive sputtering using an Al metal target and a mixture of $\mathrm{N}_{2} / \mathrm{Ar}$ gases with $0-25 \% \mathrm{Ar}$. The RF magnetron power was varied from 200 to $400 \mathrm{~W}$, and the substrates were not intentionally heated during deposition. The thickness of the AlN films, given in Table I, was measured by mechanical stylus profilometry, with an accuracy of $5 \mathrm{~nm}$. Atomic force microscopy (AFM) indicated that the surface roughness of the as-deposited layers was about $1 \mathrm{~nm}$ rms. X-ray diffraction (XRD) measurements indicated that the AlN structure varied from microcrystalline (weak, broad XRD peaks), to polycrystalline depending on the sputtering parameters. Higher RF powers and low pressures produced stronger AlN peaks. The AlN samples reported here had relatively weak XRD peaks, indicating microcrystalline structure with multiple orientations, but with the (110) plane preferentially oriented parallel to the (100) substrate. Additional details of the processing were given previously [20]-[22]

Oxidation was performed in a horizontal quartz furnace tube with dry $\mathrm{O}_{2}$ at temperatures ranging from 800 to $1100{ }^{\circ} \mathrm{C}$, for durations of $1-3 \mathrm{~h}$. XRD measurements of the oxide showed relatively weak peaks corresponding to several phases including $\alpha-\mathrm{Al}_{2} \mathrm{O}_{3}$ (sapphire), $\delta-\mathrm{Al}_{2} \mathrm{O}_{3}$, and $\theta-\mathrm{Al}_{2} \mathrm{O}_{3}$ [22], indicating that the oxide was microcrystalline and nearly amorphous. Table I shows the oxidation durations, temperatures, and the range of sublayer thickness. Shorter times and lower temperatures produced sublayers of incompletely oxidized AlN. Longer times and higher temperatures produced stronger $\mathrm{Al}_{2} \mathrm{O}_{3}$ peaks with fully oxidized $\mathrm{AlN}$, and sometimes $\mathrm{SiO}_{2}$ from the oxidation of the underlying Si substrate. The mechanism for the formation of $\mathrm{SiO}_{2}$ at the $\mathrm{Si}$ interface is not understood because the diffusivity of $\mathrm{O}$ in sapphire is negligible at $1100{ }^{\circ} \mathrm{C}(D=2 \times$ $10^{-16} \mathrm{~cm}^{2}-\mathrm{s}^{-1}$ at $\left.1500{ }^{\circ} \mathrm{C}\right)$ [25]. It may be that the layers are porous.

The film composition was measured using Rutherford backscattering spectrometry (RBS), and secondary ion mass spectrometry (SIMS). The RBS data were analyzed using RUMP software simulations [26], which yielded thickness profiles with $10 \mathrm{~nm}$ accuracy for the layers reported here. RBS indicated that the as-deposited AlN was nearly stoichiometric with a few percent of oxygen, in agreement with the XRD data. The RUMP thickness values were calibrated by ellipsometry, profilometry and atomic force microscopy. To obtain the correct layer thickness using RUMP simulations, the density values for AlN and $\mathrm{Al}_{2} \mathrm{O}_{3}$ must be corrected manually by the user [27]. For samples in the 012301 series and for samples $100601 \mathrm{~d}$ and e, there was no evidence for $\mathrm{SiO}_{2}$.

The oxide was nearly stoichiometric $\mathrm{Al}_{2} \mathrm{O}_{3}$, with residual $\mathrm{N}$ less than 5\% (the detection limit). As described previously [21], the thickness values given in Table I were simulated assuming three abrupt layers $\left(\mathrm{Al}_{2} \mathrm{O}_{3}, \mathrm{AlN}\right.$, and $\left.\mathrm{SiO}_{2}\right)$ with no interface mixing. Therefore, the evidence for homogeneous layers thinner than $50 \mathrm{~nm}$ may not be physically valid because of interface roughness and composition mixing. AFM measurements indicated that the oxide surface roughness was about $1.2 \mathrm{~nm}$ rms.

Metal-insulator-silicon (MIS) capacitors were fabricated using standard optical lithography. Electrical contacts of $100-\mathrm{nm}$ thick Al metal were evaporated onto the top of the oxide and onto the bottom of the Si substrate. Using photolithographic liftoff, the top contacts were patterned into circular dots with areas of $8 \times 10^{-4} \mathrm{~cm}^{2}$ for samples in the series 100601 , and $3.14 \times 10^{-4} \mathrm{~cm}^{2}$ for samples in the series 012301 . 


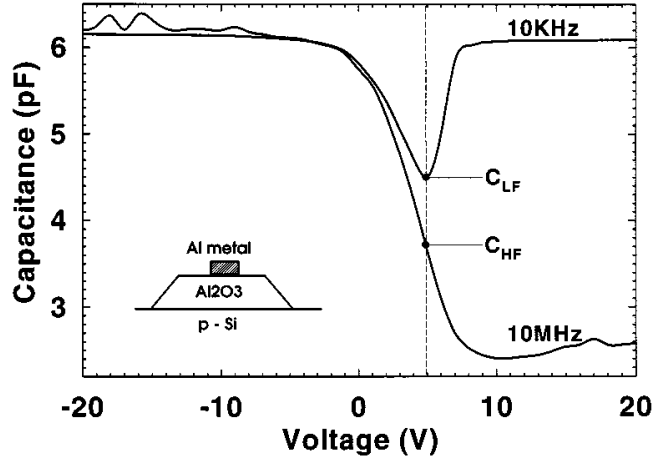

Fig. 1. The frequency dependence of the $C-V$ characteristics at room temperature for an $\mathrm{Al}_{2} \mathrm{O}_{3}$ MIS capacitor with the AlN oxidized at $1000{ }^{\circ} \mathrm{C}$ for $1 \mathrm{~h}$ (sample $100601 \mathrm{c}$ ). The characteristics indicate the accumulation of holes at negative bias, the depletion of the $\mathrm{Si}$ surface at slightly positive bias, and the inversion of the $\mathrm{Si}$ surface at higher positive bias at low frequencies The properties of the sample are given in Tables I and II. The relatively smal flatband voltage corresponds to a low oxide defect density. The capacitances at low frequency $C_{l f}$ and high frequency $C_{h f}$ were used to calculate the interface trap density $D_{i t}$. The inset shows the MIS structure with electrical contacts.

\section{RESULTS}

\section{A. Capacitance-Voltage Measurements}

The capacitance-voltage $(C-V)$ characteristics yielded the bulk and interface defect densities of the oxide, and were measured versus applied bias and frequency using techniques described previously [28]. The applied ac voltage had a peak-to-peak altitude of $50 \mathrm{mV}$. Fig. 1 shows the $C-V$ curves for a fully oxidized sample at high and low frequencies, exhibiting the $\mathrm{Si}$ surface charge regimes of electron accumulation, depletion, and inversion, similar to $\mathrm{SiO}_{2}$ capacitors [29]. At negative dc bias, the net capacitance equaled the oxide capacitance $\mathrm{C}_{\mathrm{ox}}$, due to the accumulation of holes at the p-type $\mathrm{Si}$ surface. Slightly more positive voltages decreased the net capacitance due to the series connection of the oxide and the $\mathrm{Si}$ surface depletion capacitances. Higher positive voltages at frequencies less than the carrier generation rate increased the net capacitance to $\mathrm{C}_{\mathrm{ox}}$ due to inversion of the $\mathrm{Si}$ surface with thermally generated electrons. Surface inversion indicates that transistor operation may be possible because the Fermi level is not pinned near midgap by defects. The frequency dependence of the inversion capacitance implied that the electron generation time was $t_{\text {gen }}=1 / 100 \mathrm{kHz}=10^{-5} \mathrm{~s}$. The frequency that produced quasi-static capacitance is relatively high at $10 \mathrm{KHz}$, indicating a short carrier lifetime, perhaps due to deep levels in the $\mathrm{Si}$ created during processing.

The flatband voltage is given by $V_{\mathrm{FB}}=\Phi_{\mathrm{MS}}-Q_{\mathrm{ox}} / C_{\mathrm{ox}}$, where $\Phi_{\mathrm{MS}}$ is the Al-Si work function difference $(-0.92 \mathrm{~V}$ for the metal and substrates used here), and $Q_{\mathrm{ox}}$ is the net oxide trapped charge density. In this analysis, $Q_{\mathrm{ox}}$ is the first moment of the oxide charge distribution divided by the oxide thickness, and encompasses all charged defects and impurities distributed throughout the oxide including surface states [29]. samples for which the AlN is fully oxidized have a small $\mathrm{V}_{\mathrm{FB}}$ with the trapped charge density $\left(Q_{\mathrm{ox}}\right) / q$ below $10^{12} \mathrm{~cm}^{-2}$, which is comparable to device-grade $\mathrm{SiO}_{2}$ [29]. In Table II, the flatband voltage of smallest magnitude was obtained for the sample oxidized at $1000{ }^{\circ} \mathrm{C}$, indicating that oxidized AlN can have a low total defect density. We emphasize that $Q_{\mathrm{ox}}$ is not an interface parameter, but includes contributions from defects distributed throughout the oxide, and the defect density from the aluminum oxide would not be diminished even by the possibility of nearly ideal $\mathrm{SiO}_{2}$ at the $\mathrm{Si}$ interface.

Comparisons between samples having the same thickness of AlN, but with different oxidation conditions, indicated that high temperatures and long times (sample 100601 ) produced some $\mathrm{SiO}_{2}$ at the $\mathrm{Si}$ interface and a low $Q_{\mathrm{ox}}$. On the other hand, the under-oxidized sample (100 601) had a significantly higher defect density implying that the residual AIN at the Si interface is undesirable.

The density of interface traps, $D_{i t}$, describes the quality of the $\mathrm{Si}$ surface. Due to their slower response time, interface traps produced a difference in the capacitances measured at low frequency $\mathrm{C}_{\mathrm{lf}}$, and at high frequency $C_{h f}$, as shown in Fig. 1. Using a standard approach, the frequency dependence of capacitance yields $D_{i t}$ at an energy in the gap determined by the total surface potential $\phi_{\mathrm{S}}[30]$

$$
\begin{aligned}
D_{i t}\left(\phi_{s}\right)= & \left(C_{\mathrm{ox}} / q\right)\left(C_{l f} /\left(C_{\mathrm{ox}}-C_{h f}\right)-C_{h f}\right. \\
& \left./\left(C_{\mathrm{ox}}-C_{h f}\right)\right)\left(\mathrm{cm}^{-2}-\mathrm{eV}^{-1}\right)
\end{aligned}
$$

where the applied gate voltage is $V_{G}-V_{F B}=V_{\mathrm{ox}}+\phi_{s}$, and $V_{\mathrm{ox}}$ is the voltage drop across the oxide. The results in Table II are for $\phi_{s}$ near midgap where the defects have the most impact on device performance. $D_{i t}$ densities below $10^{11} \mathrm{~cm}^{-2} \mathrm{eV}^{-1}$ indicated excellent interfaces, similar to device-grade $\mathrm{SiO}_{2}$.

From the measured oxide capacitance and thickness, the dielectric constants in Table II ranged from 3 to 9, compared to 3.9 for $\mathrm{SiO}_{2}$ [29]. The dielectric constant of sapphire $\left(\alpha-\mathrm{Al}_{2} \mathrm{O}_{3}\right)$ is 10.6 [31], but it is well know that the dielectric constants vary with microstructure for many materials. It may also be that the $\mathrm{Al}_{2} \mathrm{O}_{3}$ produced by thermally oxidizing $\mathrm{AlN}$ is less dense than sapphire.

\section{B. Current-Voltage Measurements}

Current-voltage $(I-V)$ measurements were used to determine the dielectric breakdown strength and the electrical conduction mechanisms in the oxide. Using a voltage stress probe station described elsewhere [28], [32], the capacitors were biased into accumulation with the top metal contacts negative (-). The applied voltage was ramped at the relatively slow rate of $100 \mathrm{mV} / \mathrm{s}$ for better accuracy. In principle, a faster ramp rate would yield a higher breakdown field.

Fig. 2 shows the current density versus electric field $(J-E)$ characteristics of several aluminum oxide samples, including the sample of Fig. 1 and an $\mathrm{SiO}_{2}$ sample oxidized under similar conditions. The physical parameters of the samples are given in Table I. The electric field in the aluminum oxide was determined from the applied voltage using the thickness and the dielectric constants of the other layers $(\kappa=9.1$ for AlN and 3.9 for $\mathrm{SiO}_{2}$ ) [33]. The variation in $J-E$ characteristics from sample to sample were attributed to differences in oxidation conditions, sublayer composition, and structure.

Table II summarizes the electrical results. The aluminum oxide had dielectric breakdown at fields ranging from 4 to 5 $\mathrm{MV} / \mathrm{cm}$. The leakage current densities were below $1.2 \times 10^{-7}$ 
TABLE II

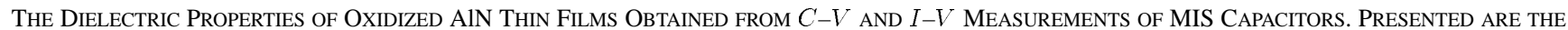
Sample Number, Oxide Capacitance per Area, Dielectric Constant, Flatband Voltage, Net Oxide Trapped Charge, Density of Interface Traps, RESISTIVITY AT 0.3 MV/cm, AND BREAKDOWN FIELD OF THE ALUMINUM OXIDE

\begin{tabular}{|c|c|c|c|c|c|c|c|}
\hline Sample & $\begin{array}{c}\mathrm{C}_{\mathrm{ox}} \\
\left(\mathrm{nF}-\mathrm{cm}^{-2}\right) \\
\end{array}$ & $\kappa_{0 x}$ & $\begin{array}{c}\mathrm{V}_{\mathrm{FB}} \\
(\mathrm{V})\end{array}$ & $\begin{array}{c}\left(Q_{0 x}\right) / q \\
\left(\mathrm{~cm}^{-2}\right)\end{array}$ & $\begin{array}{c}D_{\text {it }} \\
\left(\mathrm{cm}^{-2} \mathrm{eV}^{-1}\right)\end{array}$ & $\begin{array}{c}\rho_{\mathbf{0 X}} \\
(\Omega-\mathbf{c m})\end{array}$ & $\begin{array}{c}E_{\mathrm{BD}} \\
(\mathrm{MV} / \mathrm{cm})\end{array}$ \\
\hline $100601 \mathrm{a}$ & 13.04 & 8.45 & -1.67 & $1.46 \times 10^{11}$ & $2.26 \times 10^{10}$ & $2.2 \times 10^{13}$ & 4.6 \\
\hline $100601 \mathrm{~b}$ & 13.2 & 7.9 & -2.96 & $3.6 \times 10^{11}$ & $1.31 \times 10^{10}$ & - & \\
\hline $100601 \mathrm{c}$ & 20.5 & 9.77 & +1.13 & $6.6 \times 10^{11}$ & $1.59 \times 10^{11}$ & $4.2 \times 10^{12}$ & 4.23 \\
\hline $100601 d$ & 27.5 & 9.1 & -18.1 & $2.84 \times 10^{12}$ & $1.04 \times 10^{10}$ & $1.6 \times 10^{13}$ & 5.67 \\
\hline $100601 \mathrm{e}$ & 30 & 8.8 & -19.4 & $2.85 \times 10^{12}$ & - & - & - \\
\hline $012301 \mathrm{a}$ & & & & & & $2.9 \times 10^{12}$ & 4.99 \\
\hline $012301 b$ & 53 & 6.0 & -3 & $7.0 \times 10^{11}$ & $7.25 \times 10^{10}$ & $3.5 \times 10^{12}$ & 4.94 \\
\hline $012301 \mathrm{c}$ & & & & & & $1.3 \times 10^{12}$ & 5.32 \\
\hline SO9001 & & & & & & $1.9 \times 10^{13}$ & 10.3 \\
\hline SO9002 & & & & & & $2.8 \times 10^{13}$ & \\
\hline SO9003 & & & & & & $3.5 \times 10^{13}$ & 8.27 \\
\hline
\end{tabular}

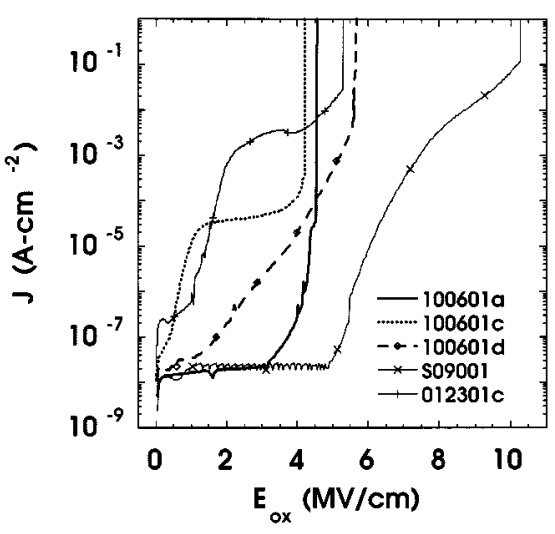

Fig. 2. The dependence of leakage current density on oxide electric field for MIS capacitors with AlN oxidized at $1100{ }^{\circ} \mathrm{C}$ for $2 \mathrm{~h}, 1000 \mathrm{C}$ for $1 \mathrm{~h}$, and $900^{\circ} \mathrm{C}$ for $1 \mathrm{~h}$ (samples $100601 \mathrm{a}, \mathrm{c}$, and d, respectively), thinner AlN oxidized at $900^{\circ} \mathrm{C}$ for $3 \mathrm{~h}(012301 \mathrm{c})$, and $\mathrm{SiO}_{2}$ oxidized at $900{ }^{\circ} \mathrm{C}$ for $1 \mathrm{~h}(\mathrm{SO}-9001)$. Properties are given in Tables I and II., and the shapes of the curves are discussed in the text. Dielectric breakdown occurred in the range from 4 to $5 \mathrm{MV} / \mathrm{cm}$ for the $\mathrm{Al}_{2} \mathrm{O}_{3}$, and near $10 \mathrm{MV} / \mathrm{cm}$ for the $\mathrm{SiO}_{2}$.

$\mathrm{A} \mathrm{cm}^{-2}$ at fields under $0.3 \mathrm{MV} / \mathrm{cm}$, corresponding to resistivities $\rho_{\text {ox }}$ greater than $10^{12} \Omega-\mathrm{cm}$. The resistivities agreed reasonably with the published value for sapphire $\left(10^{14} \Omega-\mathrm{cm}\right)$ but the breakdown strength of the samples was higher than the value accepted for bulk sapphire $(0.5 \mathrm{MV} / \mathrm{cm})$ [31].

Sample $100601 \mathrm{c}$ has a current density that increased and then saturated at about $4 \times 10^{-5} \mathrm{~A} \mathrm{~cm}^{-2}$ at fields near $1-3 \mathrm{MV} / \mathrm{cm}$, and then increased again. This behavior is under study, but has been observed in ultrathin $\mathrm{SiO}_{2}$ layers for which the constant current plateaus were attributed to phonon-assisted tunneling in neutral traps [2]. Another possibility for the current plateaus is series resistance in the test structure. For sample $100601 \mathrm{c}$, the increase in current at low fields may be due to breakdown at defects or weak spots in the dielectric, followed by a mechanism of self-healing [34], [35]. Small dark spots were observed by visual microscopy on the metal surface, and it is possible that localized current surges evaporated small regions of the Al metal contact from the surface, preventing further conduction through that spot.

In comparison, the $\mathrm{SiO}_{2}$ sample had relatively low current up to $5 \mathrm{MV} / \mathrm{cm}$, followed by increasing current with dielectric breakdown near $10 \mathrm{MV} / \mathrm{cm}$, in agreement with the accepted breakdown field of $10 \mathrm{MV} / \mathrm{cm}$ for thick $\mathrm{SiO}_{2}$ [10]. Although the breakdown field of aluminum oxide was lower than for $\mathrm{SiO}_{2}$, the breakdown voltage may be similar for optimized MIS devices having the same capacitance because of the higher dielectric constant of aluminum oxide.

\section{Analysis of Leakage Current and Dielectric Breakdown}

To determine the physical mechanisms responsible for leakage, the dependence of current on electric field was compared for two transport mechanisms known to be important for tunneling in insulators: Fowler-Nordheim (FN) tunneling and Frenkel-Poole emission.

The FN mechanism describes the tunneling of electrons from the metal into the conduction band of an insulator, with a dependence of current density on oxide electric field strength $E_{\mathrm{ox}}$ given by [10]

$$
J_{\mathrm{FN}}=a E_{\mathrm{ox}}^{2} \exp \left[-b / E_{\mathrm{ox}}\right] .
$$

The constants $a$ and $b$ are

$$
a=q^{2} /\left(8 \pi h \phi_{b}\right)=1.538 \times 10^{-6}\left(\phi_{b}\right)^{-1} \mathrm{~A}-\mathrm{V}^{-2}
$$

and

$$
\begin{aligned}
b & =8 \pi\left(2 m^{*}\right)^{1 / 2}\left(q \phi_{b}\right)^{3 / 2} /(3 h q) \\
& =68\left(m^{*} / m_{o}\right)^{1 / 2}\left(\phi_{b}\right)^{3 / 2} \mathrm{MV} / \mathrm{cm}
\end{aligned}
$$

where 


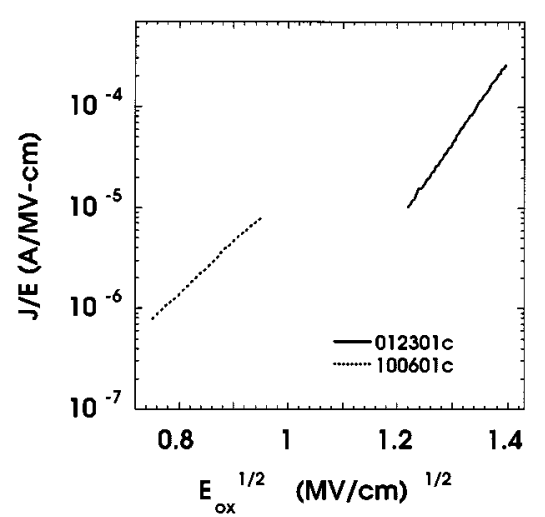

Fig. 3. The current density versus electric field characteristics at room temperature for two aluminum oxide MIS capacitors (sample 100601c oxidized at $1000{ }^{\circ} \mathrm{C}$ for $1 \mathrm{~h}$ and sample $012301 \mathrm{c}$ oxidized at $900{ }^{\circ} \mathrm{C}$ for $3 \mathrm{~h}$ ). Data are presented as a Frenkel-Poole plot showing the dependence of the leakage current density divided by the oxide electric field versus the square root of electric field. The linear slopes imply Frenkel-Poole emission in the $\mathrm{Al}_{2} \mathrm{O}_{3}$.

$h \quad$ Planck's constant;

$q$ magnitude of the electron charge;

$q \phi_{b} \quad$ energy barrier height between the oxide and the metal contact (about $3.19 \mathrm{eV}$ for $\mathrm{Al}$ on $\mathrm{SiO}_{2}[36]$ );

$m^{*} \quad$ electron effective mass for tunneling;

$m_{0}$ electron rest mass.

For $\mathrm{SiO}_{2}$, the effective mass of a tunneling electron ranges from $m^{*}=0.3 m_{o}$ [37] to $0.5 m_{0}$ [1].

Frenkel-Poole emission describes the field enhanced thermal excitation of trapped electrons into the oxide conduction band, with a dependence of current density on oxide electric field given by [10]

$$
J_{\mathrm{FP}}=c E_{\mathrm{ox}} \exp \left[\left(\left(d E_{\mathrm{ox}}\right)^{1 / 2}-\phi_{t}\right) q / k_{b} T\right]
$$

where

$k_{b} \quad$ Boltzmann's constant;

$T$ measurement temperature;

c a constant that depeðds on the trap density $N_{t}$ [38][39];

d $q / \pi \varepsilon_{i}$;

$\varepsilon_{\mathrm{i}} \quad$ total electric permittivity of the insulator.

The energy $q \phi_{t}$ is the depth of the oxide trap potential well, which differs from the barrier height for FN tunneling in (2).

Unlike FN tunneling, Frenkel-Poole emission is explicitly temperature dependent; higher temperatures reduce the current and the effect of the field on the current. Both tunneling mechanisms, however, are affected by the temperature dependence of the bandgap, the barrier heights, and the carrier occupation statistics.

Fig. 3 shows a Frenkel-Poole plot [40] of current density versus oxide electric field for two aluminum oxide samples of different thicknesses at room temperature. Linear slopes imply Frenkel-Poole emission, which occurs at higher fields for the thinner aluminum oxide sample (012301c). Frenkel-Poole emission is responsible for tunneling in $\mathrm{Si}_{3} \mathrm{~N}_{4}$ [40]. Included purely for comparison, Fig. 4 shows a FN plot [28], [41] of current density versus oxide field for a conventional MOS

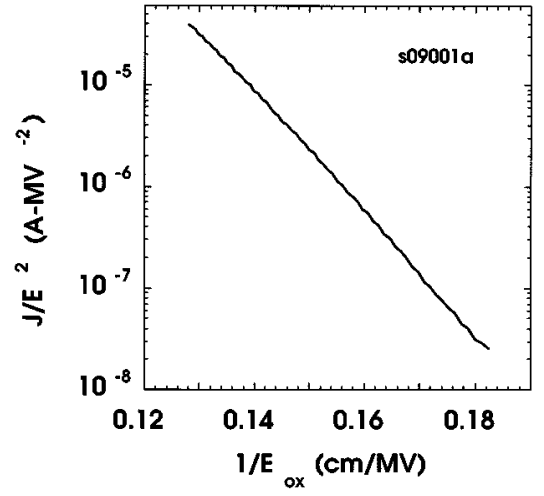

Fig. 4. The current density versus electric field characteristics of a $\mathrm{SiO}_{2} \mathrm{MOS}$ capacitor (sample SO-9001 oxidized at $900{ }^{\circ} \mathrm{C}$ for $1 \mathrm{~h}$ ). Data are presented as a FN plot showing the dependence of leakage current density divided by the oxide electric field squared versus the reciprocal electric field. The linear slope implies $\mathrm{FN}$ tunneling in $\mathrm{SiO}_{2}$.

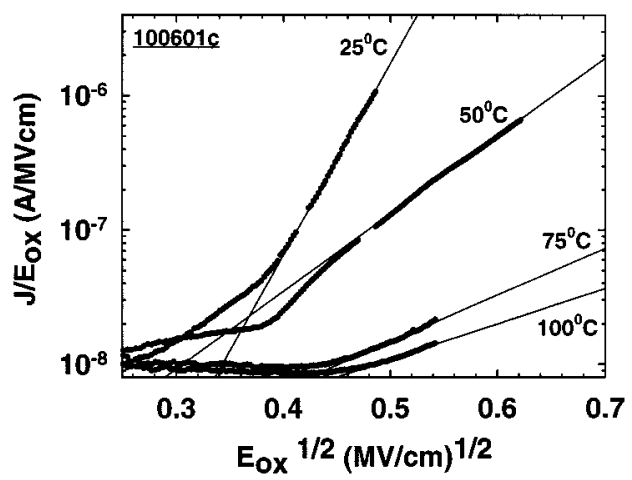

Fig. 5. Frenkel-Poole plot showing the current density versus oxide electric field characteristics at four measurement temperatures for an aluminum oxide MIS capacitor (sample $100601 \mathrm{c}$ oxidized at $1000^{\circ} \mathrm{C}$ for $1 \mathrm{~h}$ ). Linear slopes and the strong dependence on temperature imply Frenkel-Poole emission.

capacitor of aluminum metal- $\mathrm{SiO}_{2}-\mathrm{Si}$. The linear slope covering several orders of magnitude corroborates FN tunneling in $\mathrm{SiO}_{2}$. When presented as a FN plot, the aluminum oxide data was not linear, implying that FN tunneling did not occur in the aluminum oxide.

\section{Temperature Dependence of Current-Voltage Characteristics}

For further insight into the aluminum oxide conduction, the temperature variation of the $J-E$ characteristics is presented as a Frenkel-Poole plot in Fig. 5. Linear regions imply Frenkel-Poole emission, with the current decreasing exponentially with temperature, as given by (5), with the effect of the electric field on the current being opposite to the effect of the trap depth. The terms in the numerator of the exponent in (5) can be considered as a field dependent effective activation energy, $E_{\text {act }}=q\left(d E_{\mathrm{ox}}\right)^{1 / 2}-q \phi_{t}$.

Fig. 6 presents an Arrhenius plot for the sample of Fig. 5, for currents at several electric fields below breakdown. The thermally activated behavior is consistent with Frenkel-Poole emission. The effective activation energy is related to the potential well depth $q \phi_{t}$ of the oxide traps and the square 


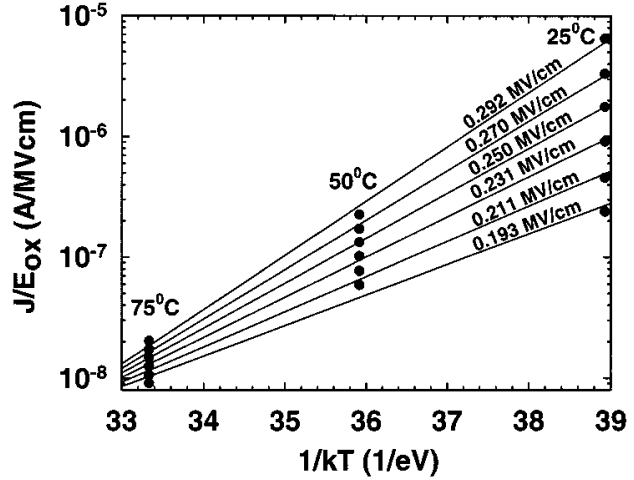

Fig. 6. Arrhenius plot of the aluminum oxide current at different values of electric field below breakdown for the sample of Fig. 5 (100601c). Solid lines are the best fits to the experimental points. The slope implies thermally activated behavior, as discussed in the text.

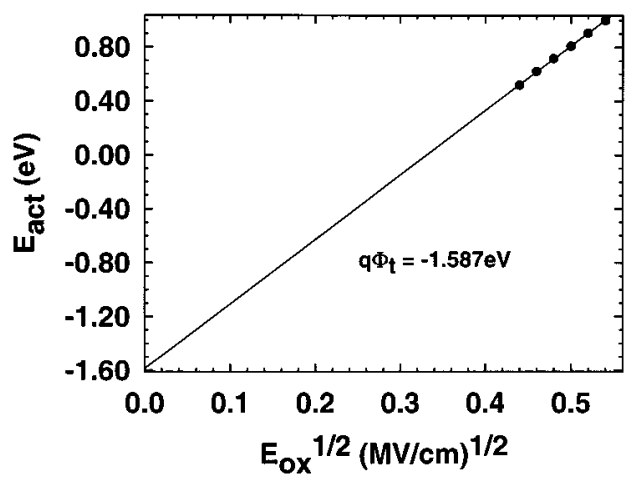

Fig. 7. Graphical determination of the Frenkel-Poole trap depth from the dependence of the effective activation energy on the square root of the electric field. By fitting the data to (5), the energy $q \phi_{t}=1.6 \mathrm{eV}$ was obtained for the depth of the oxide trap potential well.

root of electric field. Fig. 7 show a graphical determination yielding $q \phi_{t}=1.6 \mathrm{eV}$. It is not yet clear if this energy is valid generally for aluminum oxide, or just for the particular samples measured here. For comparison, a $1.3 \mathrm{eV}$ trap energy is reported for $\mathrm{Si}_{3} \mathrm{~N}_{4}$ [40].

\section{DISCUSSION}

At fields below breakdown, the Frenkel-Poole emission in $\mathrm{Al}_{2} \mathrm{O}_{3}$ is fundamentally different from conduction in $\mathrm{SiO}_{2}$, which exhibits FN tunneling. The decrease in current with increasing temperature in $\mathrm{Al}_{2} \mathrm{O}_{3}$ may be important for circuit reliability under extreme conditions.

The dielectric constant of $\mathrm{Al}_{2} \mathrm{O}_{3}$ is generally higher than for $\mathrm{SiO}_{2}$, so that gate dielectrics can be thicker for the same stored charge. For insulators less than $3 \mathrm{~nm}$ thick, tunneling occurs directly through the oxide with a probability that decreases exponentially with thickness. Thicker high dielectric gate insulators may be less susceptible to catastrophic failure and breakdown.

In principle, epitaxial techniques such as molecular beam epitaxy and chemical vapor deposition could be used to produce the starting layers of AlN for oxidation. The role of small amounts of $\mathrm{N}$ in oxidized AlN is unclear, but may be beneficial. It is well known that annealing $\mathrm{SiO}_{2}$ in an $\mathrm{N}$ ambient reduces the defect density [29], and that the nitriding of $\mathrm{SiO}_{2}$ using $\mathrm{N}_{2} \mathrm{O}$ improves circuit reliability [42], [43]. The carrier confinement properties of $\mathrm{Al}_{2} \mathrm{O}_{3}$ are expected to be similar to those of $\mathrm{SiO}_{2}$ because the bandgap of $\mathrm{Al}_{2} \mathrm{O}_{3}$ is $8.7 \mathrm{eV}$ [44], close to the $8-9 \mathrm{eV}$ bandgap of $\mathrm{SiO}_{2}$.

\section{CONCLusions}

Aluminum oxide $\left(\mathrm{Al}_{2} \mathrm{O}_{3}\right)$ was produced by thermally oxidizing AlN on $\mathrm{Si}$ substrates using oxidation conditions similar to those for $\mathrm{SiO}_{2}$. MIS devices were fabricated and had $C-V$ characteristics that exhibited the voltage-controlled charge regimes of accumulation, depletion and inversion on $\mathrm{Si}$ surfaces, with low defect densities. The best samples had net oxide trapped charge densities below $10^{11} \mathrm{~cm}^{-2}$, similar to device-grade $\mathrm{SiO}_{2}$. The dielectric constants ranged from 3 to 9 , implying that properly prepared $\mathrm{Al}_{2} \mathrm{O}_{3}$ can be thicker than $\mathrm{SiO}_{2}$ for the same gate capacitance. Prior to breakdown, the conduction mechanism in $\mathrm{Al}_{2} \mathrm{O}_{3}$ was Frenkel-Poole emission, which is qualitatively different from breakdown in $\mathrm{SiO}_{2}$. The results showed that $\mathrm{Al}_{2} \mathrm{O}_{3}$ has device-grade characteristics and holds great promise for applications including gate dielectrics for field effect transistors.

\section{ACKNOWLEDGMENT}

Regarding assistance with the measurements, the authors would like to thank D. Smith for the capacitance-voltage, C. P. Swann for RBS, K. M. Unruh for X-ray diffraction, R. G. Wilson for SIMS, and D. van der Weide and M. Barteau for AFM. The authors are also grateful to J. Comas, A. Seabaugh, G. Wilk, and J. Zavada for encouragement and useful discussions.

\section{REFERENCES}

[1] D. J. DiMaria, E. Cartier, and D. Arnold, "Impact ionization, trap creation, degradation, and breakdown in silicon dioxide films on silicon," J. Appl. Phys., vol. 73, pp. 3367-3384, 1993.

[2] K. Sakakibara, N. Ajika, K. Eikyu, K. Ishikawa, and H. Miyoshi, "Quantitative analysis of time-decay reproducible stress-induced leakage current in $\mathrm{SiO}_{2}$ films," IEEE Trans. Electron Devices, vol. 44, pp. 1002-1008, 1997.

[3] I.-H. Chen, S. E. Holland, and C. Hu, "Electrical breakdown in thin gate tunneling oxides," IEEE Trans. Electron Devices, vol. ED-32, pp. 413-416, 1985.

[4] P. Solomon, "Breakdown in silicon oxide-A review," J. Vac. Sci. Technol., vol. 14, pp. 1122-1130, 1977.

[5] J. S. Suehle and P. Chaparala, "Low electric field breakdown of thin $\mathrm{SiO}_{2}$ and films under static and dynamic stress," IEEE Trans. Electron Devices, vol. 44, pp. 801-808, 1997.

[6] J. R. Brews, "The submicron MOSFET," in High Speed Semiconductor Devices, S. M. Sze, Ed, New York: Wiley, 1990.

[7] A. Martin, J. S. Suehle, P. Chaparala, P. O'Sullivan, and A. Mathewson, "A new oxide degradation mechanism for stresses in the Fowler-Nordheim tunneling regime," in Proc. 1996 Int. Reliab. Phys. Symp., Dallas, TX, May 2, 1996, pp. 67-76.

[8] C. Hu, "Gate oxide scaling limits and projection," in IEDM Tech. Dig., 1996, pp. 319-321.

[9] W. Frensley, private communication, 1998.

[10] S. M. Sze, Physics of Semiconductor Devices, New York: Wiley, 1981, p. 405. 
[11] M. J. Ries, N. Holonyak Jr., E. I. Chen, and S. A. Maranowski, "Visible spectrum $(650 \mathrm{~nm}$ ) photopumped (pulsed, 300K) laser operation of a vertical cavity AlAs-AlGaAs/InAlP-InGaP quantum well heterostructure utilizing native oxide mirrors," Appl. Phys. Lett., vol. 67, pp. $1107-1109,1995$

[12] E. F. Schubert, M. Passlack, M. Hong, J. Mannerts, R. L. Opila, L. N. Pfeiffer, K. W. West, C. G. Bethea, and G. J. Zydzik, "Properties of Al2O3 optical coatings on GaAs produced by oxidation of epitaxial AlAs/GaAs films," Appl. Phys. Lett., vol. 64, pp. 2976-2978, 1994.

[13] K.-W. Kwon, C.-S. Kang, S. O. Park, H.-K. Kang, and S. T. Ahn, "Thermally robust $\mathrm{TaO}$ capacitor for the 256-Mbit DRAM," IEEE Trans. Electron Devices, vol. 43, pp. 919-923, 1996.

[14] K.-M. Lin, C.-Y. Kwok, and R.-S. Huang, "Integrated thermo-capacitive type MOS flow sensor," IEEE Electron Device Lett., vol. 17, pp. 247-249, 1996

[15] J. W. Diggle and A. K. Vijh, Eds., Oxides and Oxide Films, New York: Marcel Dekker, 1976, vol. 4.

[16] G. T. Cheney, R. M. Jacobs, H. W. Korb, H. E. Nigh, and J. Stack, IEDM Tech. Dig, 1967.

[17] W.-H. Lee, J. T. Clemens, R. C. Keller, and L. Manchanda, "A novel high $\mathrm{K}$ inter-poly dielectric (IPD), A12O3 for low voltage/high speed flash memories: erasing in msecs at $3.3 \mathrm{~V}$," in Tech. Dig. 1997 Symp. VLSI Technol., Feb. 1998, pp. 117-118.

[18] K. S. Stevens, M. Kinniburgh, A. F. Schwartzman, A. Ohtani, and R Beresford, "Demonstration of a silicon field effect transistor using AlN as the gate dielectric," Appl. Phys. Lett., vol. 66, pp. 3179-3181, 1995.

[19] F. Ansart, H. Ganda, R. Saporte, and J. P. Traverse, "Study of the oxidation of aluminum nitride coatings at high temperature," Thin Solid Films, vol. 260, pp. 38-46, 1995.

[20] E. A. Chowdhury, J. Kolodzey, J. Olowolafe, G. Qui, G. Katulka, D. Hits, M. Dashiell, D. van der Weide, C. P. Swann, and K. M. Unruh, "Thermally oxidized AlN thin films for device insulators," Appl. Phys. Lett., vol. 70, pp. 2732-2734, 1997

[21] J. Kolodzey, E. A. Chowdhury, G. Qui, J. Olowolafe, C. P. Swann, K. M. Unruh, J. Suehle, R. G. Wilson, and J. M. Zavada, "The effects of oxidation temperature on the capacitance-voltage characteristics of oxidized AlN films on Si," Appl. Phys. Lett., vol. 71, pp. 3802-3804, 1997.

[22] E. A. Chowdhury, G. Qui, M. Dashiell, S. Woods, J. O. Olowolafe, D. van der Weide, C. P. Swann, K. M. Unruh, and J. Kolodzey, "Optical and electronic properties of oxidized AlN thin films grown at different temperatures," J. Electron. Mater., vol. 27, pp. 918-922, 1998.

[23] J. Olowolafe, private communication, 1998

[24] M. Aguilar-Frutis, M. Garcia, and C. Falcony, "Optical and electrica properties of aluminum oxide films deposited by spray pyrolysis," Appl. Phys. Lett., vol. 72, pp. 1700-1702, 1998.

[25] K. P. R. Reddy and A. R. Cooper, "Oxygen diffusion in sapphire," $J$. Amer. Ceram. Soc., vol. 65, pp. 634-638, 1982.

[26] L. R. Doolittle, "Rutherford universal manipulation program," Nucl. Instrum. Meth. B, vol. 9, pp. 344-351, 1985.

[27] V. Aubry-Fortuna, private communication, 1998.

[28] J. S. Suehle, P. Chaparala, C. Messick, W. M. Miller, and K. C. Boyko, "Field and temperature acceleration of time-dependent dielectric breakdown in intrinsic thin $\mathrm{SiO}_{2}$," in Proc. 1994 Reliab. Phys. Symp., San Jose, CA, Apr. 12-14, 1994, pp. 120-125.

[29] E. H. Nicollian and J. R. Brews, MOS Physics and Technology, New York: Wiley, 1982.

[30] R. Castagne and A. Vapaille, "Description of the $\mathrm{SiO}_{2}-\mathrm{Si}$ interface properties by means of very low frequency MOS capacitance measurements," Surf. Sci., vol. 28, pp. 157-193, 1971.

[31] Handbook of Thin Film Technology, L. I. Maissel and R. Glang, Eds., McGraw-Hill, New York, 1983, p. 6.12.

[32] P. Chaparala, J. S. Suehle, C. Messick, and M. Roush, "Electric field dependent dielectric breakdown of intrinsic $\mathrm{SiO}_{2}$ films under dynamic stress," Proc. 1996 Int. Reliab. Phys. Symp., pp. 62-66, Apr. 30-May 2, 1996.

[33] O. Madelung, Ed., Data in Science and Technology, Semiconductors, Group IV Elements and III-V Compounds. Berlin, Germany: Springer-Verlag, 1991.

[34] D. J. Dumin, S. K. Mopuri, S. Vanchinathan, R. S. Scott, R. Subramoniam, and T. G. Lewis, "High field related thin oxide wearout and breakdown," IEEE Trans. Electron Devices, vol. 42, pp. 760-772, 1995.

[35] M. Nafria, J. Sune, D. Yelamos, and X. Aymerich, "Degradation and breakdown of thin silicon dioxide films under dynamic electrical stress," IEEE Trans. Electron Devices, vol. 43, pp. 2215-2226, 1996.

[36] T. Yoshida, D. Imafuku, J. L. Alay, S. Miyazaki, and M. Hirose, "Quantitative analysis of tunneling current through ultrathin gate oxides," Jpn. J. Appl. Phys., vol. 34, pp. L903-L906, 1995.
[37] B. Brar, G. D. Wilk, and A. C. Seabaugh, "Direct extraction of the electron tunneling effective mass in ultrathin $\mathrm{SiO}_{2}$," Appl. Phys. Lett., vol. 69, pp. 2728-2730, 1996.

[38] J. Frenkel, "On pre-breakdown phenomena in insulators and electronic semiconductors," Phys. Rev., vol. 54, pp. 647-648, 1938.

[39] J. Frenkel, "On pre-breakdown phenomena in insulated and electronic semiconductors," in Tech. Phys. USSR, 1938, vol. 5, p. 2951.

[40] S. M. Sze, "Current transport and maximum dielectric ðtrength of silicon nitride films," J. Appl. Phys., vol. 38, pp. 2951-2956, 1967.

[41] Y. Nissan-Cohen, J. Shappir, and D. Fr $\Omega$ an-Bentchkowsky, "Measurement of Fowler-Nordheim tunneling currents in MOS structure under charge trapping conditions," Solid-State Electron., vol. 28, pp. 717-720, 1985.

[42] X. Zeng, P. T. Lai, and W. T. Ng, "AC hot-carrier- induced degradation in NMOSFET's with $\mathrm{N}_{2} \mathrm{O}$-based gate dielectrics," IEEE Electron Device Lett., vol. 18, pp. 39-41, 1997.

[43] X. Zeng, P. T. Lai, and W. T. Ng, "A novel technique of $\mathrm{N}_{2} \mathrm{O}$ treatment on $\mathrm{NH}_{3}$-nitrided oxide as gate dielectric for nMOS transistors," IEEE Trans. Electron Devices, vol. 43, pp. 1907-1913, 1996.

[44] P. Balk, The $\mathrm{Si}_{\mathrm{SiO}}$ System. Amsterdam, The Netherlands: Elsevier, 1988.

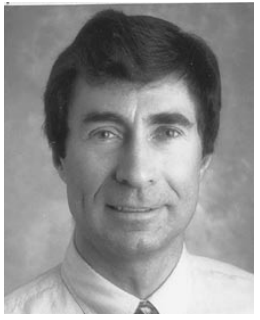

James Kolodzey (M'74-SM'90) received the Ph.D degree in electrical engineering from Princeton University, Princeton, NJ, in 1986 for research on SiGe alloys.

He was with IBM Corporation and Cray Research from 1975 to 1982 . From 1986 to 1989 , he was an Assistant Professor of Electrical Engineering at the University of Illinois at Urbana-Champaign, where he established a laboratory for high-frequency device measurements at cryogenic temperatures. In 1987, he worked on molecular beam epitaxy with Dr. A. Y. Cho at AT\&T Bell Laboratories, Murray Hill, NJ. In 1990, he worked on SiC and $\mathrm{SiGeC}$ alloys with Dr. F. Koch and Dr. R. Schwarz at the Technical University of Münich, Münich, Germany. Since 1991, he has been at the University of Delaware, Newark. In 1997, he spent nine months at the University of Paris, Orsay, France, investigating optoelectronic devices. He is currently a Professor of Electrical and Computer Engineering at the University of Delaware. His research interests include the electrical and optical properties of alloys of group IV semiconductors, and their device and circuit applications. He is investigating aluminum oxide for transistor gate dielectrics and the properties of silicon carbide alloyed with germanium.

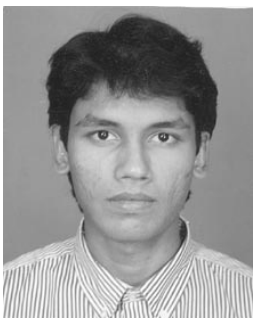

Enam Ahmed Chowdhury received the A.B. degree from Wabash College, Crawfordsville, IN, in 1995 Currently, he is pursuing the Ph.D. in physics at the University of Delaware, Newark.

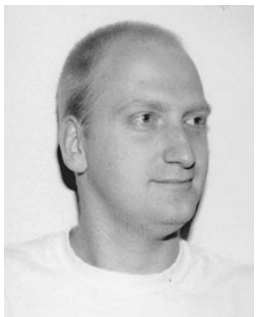

Thomas N. Adam received the B.S. degree (Diplomingeneur) in electrical engineering from the Technical University of Chemnitz-Zwickau, Germany, in 1997. His research in the Department of Materials Science at the University of Delaware, Newark, focused on the electro-optical simulation of VCSEL diodes. His doctoral research with Prof. James Kolodzey in the Department of Electrical and Computer Engineering at the University of Delaware involves the growth of novel dielectric materials, such as $\mathrm{Al}_{2} \mathrm{O}_{3}$ for new MOS transistors. 


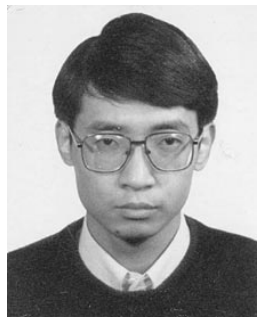

Guohua Qiu received the B.S. and M.S. degrees in material science from Shanghai Jiao Tong University, Shanghai, China, in 1987 and 1990, respectively. He received the M.S. degree in electrical engineering from the University of Delaware, Newark, in 1997. His M.S. dissertation was on the investigation on $\mathrm{Al}_{x} \mathrm{In}_{1-x} \mathrm{~N}$ and $\mathrm{AlO}_{x} \mathrm{~N}_{y}$ thin films.

From 1990 to 1995, he was a Lecture and Research Associate at Shanghai Jiao Tong University and engaged in research of intermetallic composite materials. He served as a Research Assistant at the University of Delaware from 1995 to 1997 . He is currently a Product Engineer at Dallas Semiconductor, Dallas, TX.

I. Rau was born in Karl-Marx-Stadt, Germany, in 1975. He was admitted to the undergraduate program in physics at the Chemnitz University of Technology, Chemnitz, Germany, in 1993, where he is currently finishing his thesis to achieve the Dipl.-Phys. degree. His current research is focused on epitaxial silicide formation.

From 1997 to 1998, he was with the Department of Electrical and Computer Engineering, University of Delaware, Newark.

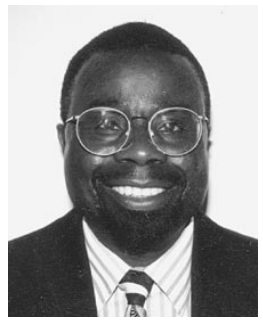

Johnson Olufemi Olowolafe received the Ph.D. degree in applied physics from the California Institute of Technology, Pasadena.

He was a World Trade Postdoctoral Fellow at the IBM T. J. Watson Research Center, Yorktown Heights immediately after graduation. After the postdoctoral training, he was a Senior Lecturer and Associate Professor at the University of Ife, Nigeria., from 1978 to 1989 . During this period, he was a Visiting Research Associate Professor at Cornell University, Ithaca, NY, for a total of two years. From 1990 to 1995, he was with Motorola, Inc., Austin, TX, where he developed the copper interconnect metallization. Since 1995, he has been an Associate Professor of Electrical and Computer Engineering at the University of Delaware, Newark. His research interests include interaction of metals with elemental and compound semiconductors, $\mathrm{Cu}$ and $\mathrm{Al}$ interconnect metallization on microelectronic devices, development of novel gate electrode materials, and fabrication of semiconductor devices. He has coauthored over 100 journal articles and seven patents.

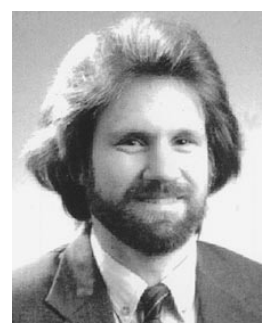

John S. Suehle (S'81-M'82-SM'95) received the B.S., M.S., and Ph.D. degrees in electrical engineering from the University of Maryland, College Park, in 1980, 1982, and 1988, respectively. In 1981, he received a Graduate Research Fellowship with the National Institute of Standards and Technology (NIST), Gaithersburg, MD

Since 1982, he has been with the Semiconductor Electronics Division at NIST, where he is Leader of the Dielectric Reliability Metrology project. His research activities include failure and wear-out mechanisms of semiconductor devices and CMOS-compatible MEMS devices for in situ process monitoring. He serves as the chairman of the Oxide Integrity Working Group of the EIA/JEDEC 14.2 Standards Committee.

Dr. Suehle is a member of Eta Kappa Nu.

Yuan Chen received the B.S. and M.S. degrees in electrical engineering from Xi' an Jiaotong University, Xi' an, China, in 1989 and1992, respectively, and the $\mathrm{Ph}$.D. degree in reliability engineering from the University of Maryland, College Park, in 1998. She conducted her postdoctoral research with NIST/UMCP and is currently with Bell Labs, Lucent Technologies, as a Member of Technical Staff. Her present research and projects cover wafer-level reliability testing and modeling, oxide reliability measurement, ultra-thin oxide characterization, hotcarrier aging, and failure analysis. 